\title{
ORIGINAL ARTICLE \\ Epidemiological and treatment profiles of spinal cord injury in southeast Nigeria
}

\author{
OE Nwankwo ${ }^{1}$ and EO Uche ${ }^{2}$
}

\begin{abstract}
Study design: Retrospective study.
Objective: To evaluate the epidemiology and treatment outcome of spinal cord injuries (SCls) at three tertiary care centres within southeast Nigeria.

Setting: Southeast Nigeria.

Methods: Causes, seasonal variation, transportation to hospital, severity of injury, treatment and outcome of patients with SCls treated by the authors at three study locations from September 2009 to August 2012 were studied.

Results: Eighty-five patients with $\mathrm{SCl}$ had been admitted during that period to the three hospitals and were qualified for the study. The age range was $2-75$ years with a mean of 36.13 years. The 31-45 years age group is the most frequently affected. Altogether, 69 male and 16 female individuals were involved. Motor vehicle accident (MVA) (47,55.3\%) was the most frequent cause of injury. Falls from palm trees (3.5\%) were markedly reduced from what they were inferred to be $(40.2 \%)$ from a similar study in our area in 1988 . Injury peaks were observed during major festivities. Only three patients (0.035\%) were transported to care centres with an ambulance. Forty patients were classified as being affected by ASIA grade A injury, whereas 45 patients had various ASIA grades of incomplete injury. Sixty-eight patients were managed conservatively; 23 of them improved from their grades, 35 remained the same, 1 worsened, while 9 died. Of 17 patients treated operatively, 9 improved, 5 remained the same, 2 worsened and 1 died.
\end{abstract}

Conclusion: Currently, SCls reported in the three main hospitals located in southeast Nigeria are caused mainly by MVAs. SCI affects mainly male individuals and peak frequencies are observed during festivities.

Spinal Cord (2013) 51, 448-452; doi:10.1038/sc.2013.10; published online 12 March 2013

Keywords: spinal cord injury; epidemiology; treatment profile

\section{INTRODUCTION}

Spinal cord injury (SCI) occurs in southeast Nigeria with disturbing morbidity and mortality. ${ }^{1-4}$ From ancient times, the challenges of SCI care have been well recognized by clinicians worldwide. ${ }^{2,5}$ Despite well-documented works on epidemiological trends and treatment, ${ }^{6-8}$ the disability associated with the burden of SCI, especially in southeast Nigeria, remains overwhelming, ${ }^{1-4}$ justifying a further look into them in order to propose solutions aimed at minimizing the disease burden in our subregion.

Previous studies by some of the current authors involved only orthopaedic surgeons and have focused mainly on treatment, especially conservative modality, and were conducted in only one of the three care centres. ${ }^{2,3}$ In this study, orthopaedic and neurosurgeons were involved, surgical treatment besides skull traction was introduced, three care centres were involved and more attention was paid to the epidemiological features.

The care centres are the University of Nigeria Teaching Hospital (UNTH), Enugu, a tertiary referral centre in the southeast region; Federal Medical Centre (FMC), Umuahia, a tertiary referral centre in Abia state; and Hilltop hospital, a 50-bed private orthopaedic and trauma care facility in Enugu. All the centres are located in southeast Nigeria. Together, these three hospitals care for a large majority of trauma patients, especially those with SCI, in southeast Nigeria.
This study sets out to evaluate the epidemiological and treatment profiles of spinal cord-injured individuals managed by the authors in the above-mentioned care centres over a 3-year period, from September 2009 to August 2012.

\section{PATIENTS AND METHODS}

Patients with SCI treated by the authors at the three study locations in southeast Nigeria between September 2009 and August 2012 were included, and their clinical records including follow-up data were retrospectively analysed. The inclusion criterion was having complete hospital records and having sustained spinal cord dysfunction from trauma without chronic pressure sore on presentation. Patients who sustained SCI before the commencement of our study and those who were initially managed in other hospitals but were referred to the centres of our current study for treatment of chronic pressure ulcers during the period of our study were excluded.

The demographic data were recorded. For every case, the cause, period, mechanism, neurological level and severity of injury, the mode of transportation, associated injuries, radiological/MRI findings, complications, treatment and outcome data were acquired and analysed using the Statistical Package for Social Sciences (SPSS) version 15 (SPSS Inc., Chicago, IL, USA).

The 12-week programme for the management of spinal cord-injured patients, with the aid of relatives, ${ }^{2}$ was used for those managed conservatively. Skull traction for reduction and initial immobilization was also used for those with cervical spine fracture.

${ }^{1}$ Orthopaedic Surgery Unit, Department of Surgery, University of Nigeria Teaching Hospital (UNTH) Enugu/Hilltop Hospital, Enugu, Nigeria and ${ }^{2}$ Neurological Surgery Unit, Department of Surgery, University of Nigeria Teaching Hospital, Enugu, Nigeria

Correspondence: Dr OE Nwankwo, Orthopaedic Surgery Unit, Department of Surgery, University of Nigeria Teaching Hospital (UNTH) Enugu/Hilltop Hospital, Ituku-Ozalla, Enugu Portharcourt, Enugu, Enugu State 40001, Nigeria.

E-mail: okechukwu.nwankwo@unn.edu.ng

Received 3 November 2012; revised 19 January 2013; accepted 23 January 2013; published online 12 March 2013 
Surgical treatment of SCI was performed for some patients in our study. Indications for surgical treatment included penetrating injury with cerebrospinal fluid leak, presence of foreign bodies in the spinal canal, spinal instability, evidence of continuing cord compression, and reduction and realignment of the spine with severe vertebral deformity from trauma.

Surgical procedures performed included laminectomy for canal decompression, with or without fusion for penetrating injuries with foreign bodies in the spinal canal. Dural repair was performed in all cases of cerebrospinal fluid leakage. Posterior spinous process wiring (Roger's technique) was performed in unstable cervical spine fractures. Surgical fusion of lumbar and thoracic fractures was performed using low-cost vertical struts (modified from Rush nails) and the cerclage wire technique. These methods of fusion were used to reduce the financial burden on our patients, most of whom had a low income status and no insurance cover.

The American Spinal Injury Association (ASIA) impairment scale was used in assessment both on admission and at discharge. Any improvement or deterioration in spinal injury grade during treatment and follow-up was documented.

Patients were followed up for 6 months. All the cases of death were recorded.

\section{RESULTS}

Eleven patients were excluded because they had sustained SCI before the commencement of our study, although they were referred for treatment of pressure ulcers during the period of study. In all, 85 patients were qualified for the study. Of them, 36 were treated in UNTH, 39 in FMC and 10 in Hilltop hospital. The age range was $2-75$ years, with a mean of 36.1 years (s.e.m., 1.7 years) (Table 1).

There were 69 male and 16 female individuals, in the ratio 4.3:1 (M:F). With regard to their employment status, 17 were businessmen (20\%), 17 students (20\%), 12 civil servants (14.1\%), 12 artisans (14.1\%) and 11 farmers (12.9\%) (see Table 2).

Motor vehicle accident (MVA) (in 47 cases (55.3\%)) and falls (in $20(23.5 \%)$ ) were the most common causes of trauma (see Table 3 ). Falls from palm trees happened in 3 cases $(3.5 \%)$, from other trees in 7 cases, from building scaffolds in 7 cases and due to other reasons in 3 cases. Falls occurred at home in 4 patients $>55$ years of age. Other causes include penetrating injury from gunshot in 7 cases $(8.2 \%)$ and SCI with foreign body in the spinal canal in 2 cases $(2.4 \%)$. The rest are assault in 6 cases $(7.1 \%)$ and landslide in 3 cases $(3.5 \%)$. Cases of assault occurred from stabbings in 3 cases $(3.5 \%)$, while in 3 cases $(3.5 \%)$ patients were hit with metal rods during interpersonal fight Peaks of injury frequencies were seen around the festive periods (Easter and Christmas) of the year (Table 4). Mode of transport to hospital from the trauma scene was mainly by commuter bus in 33 cases $(38.8 \%)$, by car in 26 cases $(30.6 \%)$, by tricycle/motorcycle in 18 cases $(21.2 \%)$ and by human ferry in 5 cases (5.9\%); ambulance transported only $3(3.5 \%)$ patients (Figure 1). None of the cases transported by human ferry improved in neurologic status following treatment; however, one-way analysis of variance showed no significant variation in outcome among the subgroups of SCI in relation to the mode of rescue: $F(0.05,3,4)=1.99, P>0.05$.

Cervical spine injury occurred in $45(52.9 \%)$ patients, thoracic spine injury in 19 (22.4\%), and lumbar spine injury in 21 (24.7\%) (Table 5).

Flexion was the most common injury mechanism, occurring in 30 $(35.3 \%)$ patients, axial injury in $14(16.5 \%)$, extension in $14(16.5 \%)$, shear injury in $11(12.9 \%)$, distraction injury in $7(8.2 \%)$ and penetrating injury in 9 (16.4\%).

At admission, 40 patients (47.1\%) had ASIA grade A injury, 10 $(11.8 \%)$ ASIA B, 19 (22.4\%) ASIA C, 15 (17.7\%) ASIA D, and $1(1.18 \%)$ patient ASIA E (Table 5).
Table 1 Age distribution

\begin{tabular}{lcr}
\hline Age group (year) & Number & Percent \\
\hline $1-15$ & 7 & 8.3 \\
$16-30$ & 28 & 32.9 \\
$31-45$ & 32 & 37.7 \\
$46-60$ & 12 & 14.1 \\
$61-75$ & 6 & 7.1 \\
Total $(n)$ & 85 & 100.0
\end{tabular}

Mean $=34.8$ years; standard error of mean (s.e.m.) $=1.7 ; 95 \%$ confidence interval $(\mathrm{Cl})$ for mean $=34.8 \pm 3.3$

Table 2 Occupational distribution

\begin{tabular}{lcr}
\hline Occupation & Number & Percent \\
\hline Students & 17 & 20.0 \\
Businessmen & 17 & 20.0 \\
Civil servants & 12 & 14.0 \\
Artisans & 12 & 14.0 \\
Farmers & 11 & 12.9 \\
Drivers & 8 & 9.4 \\
Military/police & 6 & 7.1 \\
Clergy & 1 & 1.8 \\
Toddler & 1 & 1.8 \\
Total $(n)$ & 85 & 100.0 \\
\hline
\end{tabular}

$n=85(100 \%)$.

Table 3 Causes of spinal injury

\begin{tabular}{lcr}
\hline Cause & Number & Percent \\
\hline RTA & 47 & 55.3 \\
Fall & 20 & 23.5 \\
Assault & 6 & 7.1 \\
Gunshot & 7 & 8.2 \\
Foreign body in the spinal canal & 2 & 2.4 \\
Landslide & 3 & 3.5 \\
Total $(n)$ & 85 & 100.0
\end{tabular}

Abbreviation: RTA, road traffic accident

$n=85(100 \%)$.

Associated injury occurred in 29 (34.1\%) patients, including chest lesion in 9 cases, long bone fractures in 8 , head injury in 7 and abdomen lesion in 5 patients. In all, $68(80 \%)$ patients were managed conservatively, while $17(20 \%)$ patients had surgical treatment with regard to their column lesion. Surgical treatment of the spinal lesion included laminectomy and debridement with dural repair in 7 (8.2\%) patients for penetrating injury, and spinal fusion in $10(11.8 \%)$ patients for the presence of instability. There were 4 cases of cervical spine injury, 2 cases of thoracic injury and 4 cases of lumbar spine injury. Two of the 17 patients had ASIA grade A injury (complete injury) and 15 had incomplete injury. Of the two patients in ASIA grade $\mathrm{A}$, one patient died after surgery and the other remained in the same grade. Out of the 15 patients who had incomplete injury, 9 improved their grades, 4 remained in their grades, but 2 worsened and moved a grade backwards (Table 6). Thirteen cases treated conservatively had indications for surgery but could not afford it. This happened in seven cases with ASIA grade A, two cases with ASIA B, three cases with ASIA C and one case with ASIA D. For this category of patients, five cases with ASIA A remained the same, while two died. 
Table 4 Distribution by month of occurrence

\begin{tabular}{lcr}
\hline Month & Number & Percent \\
\hline January & 11 & 12.9 \\
February & 3 & 3.5 \\
March & 5 & 5.9 \\
April & 9 & 10.6 \\
May & 4 & 4.7 \\
June & 5 & 5.9 \\
July & 4 & 4.7 \\
August & 5 & 5.9 \\
September & 7 & 4.7 \\
October & 7 & 5.9 \\
November & 10 & 8.2 \\
December & 15 & 8.2 \\
Total $(n)$ & 85 & 100.0 \\
\hline
\end{tabular}

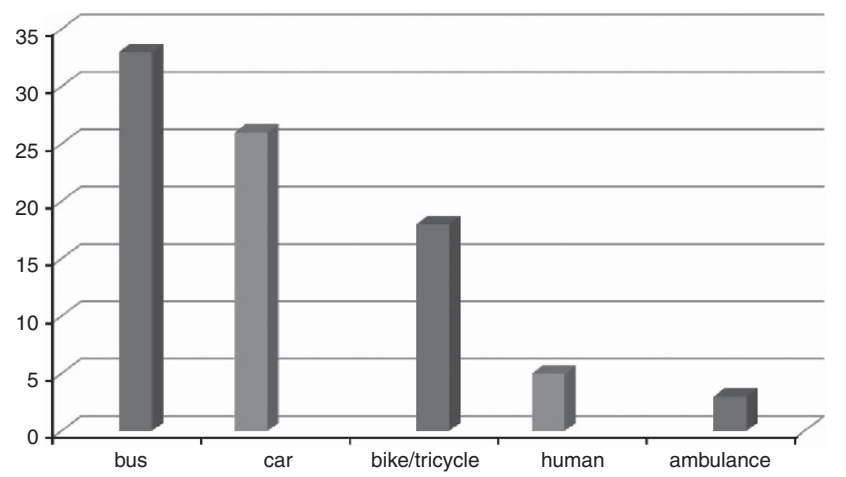

Figure 1 Histogram showing distribution of patients by mode of transport to care facility $\left(F=1.99, \mathrm{df}_{1}=3, \mathrm{df}_{2}=4, P>0.05\right)$.

Of the two patients with ASIA B grade, one patient remained the same, while one died; one of the cases with ASIA C moved two grades backward, while the two other cases as well as the patient with ASIA D grade remained neurologically stable.

Complications were recorded in 41 cases during treatment and these included pressure ulcer in $14(16.5 \%)$, urinary tract infection in $10(11.8 \%)$, respiratory tract infection in $6(7.1 \%)$, deep vein thrombosis in $5(5.9 \%)$, aspiration in $4(4.7 \%)$ and wound infection in $2(2.4 \%)$ patients. Outcome assessment of all cases with ASIA grading at discharge showed improvement in 21 cases, of which 19 cases had incomplete injury, while 2 had complete injury. In 50 patients the condition remained the same. In four patients the neurological condition worsened; three had complete injury, while one had incomplete injury (Table 6).

In all, $10(11.8 \%)$ patients died, 7 of them with complete injury ASIA A, 2 ASIA B and 1 ASIA C. Aspiration was the cause of death in three cases, respiratory failure in two, pulmonary embolism in two and sepsis in three patients. Among the 10 patients who died, 7 had cervical injury, 2 had thoracic injury and 1 had a lumbar injury.

\section{DISCUSSION}

Spinal cord injury, especially when it is neurologically complete, is a devastating condition both for the patient and for his/her relatives, because of the degree of disability and cost associated with it. It also poses a significant challenge to health-care givers in terms of the burden of care..$^{2-6}$ Therefore, every effort to better understand and manage the disease is an effort in the right direction.
Table 5 Injury severity at admission versus site of injury

\begin{tabular}{lccc} 
ASIA Grade & Cervical $(\mathrm{n}=45)$ & Thoracic $(\mathrm{n}=19)$ & Lumbar $(\mathrm{n}=21)$ \\
\hline A & 20 & 13 & 7 \\
B & 5 & 2 & 3 \\
C & 11 & 3 & 5 \\
D & 8 & 1 & 6 \\
E & 1 & 0 & 0 \\
\hline
\end{tabular}

Abbreviation: ASIA, American Spinal Injury Association.

Table 6 Relationship between ASIA grade, treatment modality and outcome

\begin{tabular}{|c|c|c|c|c|}
\hline \multicolumn{5}{|c|}{ Treatment outcome } \\
\hline Treatment modality & Death & Worse & $\begin{array}{c}\text { Same } \\
\text { condition }\end{array}$ & $\begin{array}{l}\text { Improved (grade of } \\
\text { improved pts) }\end{array}$ \\
\hline Operative $(\mathrm{n}=17)$ & 1 & 2 & 5 & 9 \\
\hline ASIA A $(n=2)$ & 1 & - & 1 & 0 \\
\hline $\mathrm{ASIA} \mathrm{B}(n=2)$ & 0 & $\begin{array}{c}1 \text { (ASIA } \\
\text { A) }\end{array}$ & 0 & 1 (D:1 pt) \\
\hline ASIA C $(n=7)$ & 0 & $\begin{array}{c}1 \text { (ASIA } \\
B)\end{array}$ & 1 & 5 (D: 3 pts; E: 2 pts) \\
\hline ASIA D $(n=5)$ & 0 & 0 & 2 & 3 (E: 3 pts) \\
\hline $\mathrm{ASIA} \mathrm{E}(n=1)$ & 0 & 0 & 1 & 0 \\
\hline $\begin{array}{l}\text { Non-operative, } \\
(\mathrm{n}=68)\end{array}$ & 9 & 1 & 35 & 23 \\
\hline ASIA A $(n=38)$ & 6 & - & 29 & 3 (C: 2 pt; D: 1 pt) \\
\hline $\mathrm{ASIA} \mathrm{B}(n=8)$ & 2 & 0 & 4 & 2 (C: 1 pt; D: 1 pt) \\
\hline ASIA C $(n=12)$ & 1 & $\begin{array}{c}1 \text { (ASIA } \\
B)\end{array}$ & 0 & 10 (D: 6 pts; E: 4 pts) \\
\hline ASIA D $(n=10)$ & 0 & 0 & 2 & 8 (E: 8 pts) \\
\hline $\mathrm{ASIA} \mathrm{E}(n=0)$ & 0 & 0 & 0 & 0 \\
\hline
\end{tabular}

Abbreviations: ASIA, American Spinal Injury Association; pt, patient.

Despite advances in the care of spinal cord-injured individuals, solutions to avoid the disabilities of permanent complete cord injury have not been found; therefore, understanding factors that contribute to the cause of the disease may help in adopting the proper prevention strategies. This is the direction in which this study is focused.

Age distribution in our study shows the highest frequency $(37.7 \%)$ in the age group of 31-45 years, followed closely (32.9\%) by the age group of 16-30 years. An earlier study in our region ${ }^{1}$ also showed the highest frequencies in the same age groups. These age groups are the most useful and active periods of life according to the experience of other authors in Nigeria. ${ }^{4,6,9}$ The male to female ratio of 4.3:1 shows a preponderance of men and is in consonance with previous studies in our area and elsewhere. ${ }^{1,3,4,6,9,10}$

Businessmen and students (20\%) were the most common groups of people involved because of their higher mobility, mostly by motor vehicles. Farmers (12.9\%) were also commonly involved and this subcategory of SCI patients sustained injury mainly from MVAs in the rural setting (in $7 / 11$ patients). Motor vehicle accident $(55.3 \%$ ) was the most common cause of SCI, followed by falls (20\%). This finding agrees with those of recent studies in our subregion, ${ }^{3,4,6}$ whereas an earlier study ${ }^{1}$ showed that falls, especially those from palm tree $(40.2 \%, 29 / 72)$, were at that time the most common cause of injury. This can be explained by the times of the studies: in the 
1980s, when the earlier study was conducted, tall palm trees were the common species in our region and oil palm was a good source of income, while recently, shorter species of palm replaced them ${ }^{1}$ and palm oil production is no more a major source of income.

The good policy of substitution through proper implementation has resulted in the reduction of spinal injuries from falls, bringing it from its unenviable first position in the earlier study ${ }^{1}$ to second in this study among the causes of spinal injuries. Adequate education and sensitization can be extended to other major causes of spinal injury in our subregion, especially road vehicle accidents, the rate of which is known to be among the highest in the world ${ }^{1}$ because of the very bad state of our road network. ${ }^{6}$ This has been achieved in other countries of the world. ${ }^{11,12}$

The frequencies of gunshot injuries and assault are higher in our study when compared with that of earlier studies, ${ }^{1,3}$ and this is explained by a rise in urban violence. The highest peak period of injury was in the last quarter of the year, which corresponds to the time of preparation and celebration of Christmas festivity, followed by another rise in the beginning of the second quarter, which is usually the period of Easter celebration. These are periods of mad rush in all activities of life in order to celebrate the festivities, especially Christmas, to the fullest.

It is of great concern that only $3.5 \%$ of cases were transported by ambulance from the scene of injury to the care centre, whereas the rest $96.5 \%$ were by unconventional means of transportation, including human ferry and motorcycle. Ironically, in our subregion, ambulances are used mainly for conveying corpses. ${ }^{4}$ This may denote the differences in our social values that may strongly and negatively affect the availability and functionality of our emergency services, as well as the dearth of skilled medical emergency staff for ambulance services.

Although no significant variation was noted among the subgroups with regard to neurologic outcome using one-way analysis of variance test $\left(F=1.99, \mathrm{df}_{1}=3, \mathrm{df}_{2}=4, P>0.05\right)$ Figure 1 , none of the patients transported by human ferry improved neurologically following treatment, suggesting that this method of rescue is not beneficial to patients with SCI and should be discouraged through proper education of the populace on the role of ambulance services as well as skilled emergency medical personnel in the rescue and transportation of patients with SCI. Cervical spine was found to be the most common tract of the spine affected by trauma.

This was also observed in our previous study, ${ }^{3}$ as well as in some other studies. ${ }^{4,5}$ Most cases of spinal injury have been managed conservatively ${ }^{13}$ and, as reported in our previous studies, ${ }^{2,3}$ we have shown the usefulness of involving patients' relatives in the nonoperative care of the spinal cord-injured. In all, 17 patients $(20 \%)$ received surgical treatment of the lesioned spine; 7 of them had operative decompression and dural repair for gunshot injury with foreign body in the spinal canal and dural lacerations. Operative decompression is generally indicated in gunshot injury to the spine with foreign body in the spinal canal, cerebrospinal fluid leak and progressive or new-onset neurological deficit. ${ }^{14}$

Owing to the high cost of conventional spinal implants and hardware, considering the low income status of most of our patients, the search for cheaper but efficient alternative methods of spinal stabilization was necessary. We used strut grafts and spinal process wire for posterior spinal stabilization. This technique has been used for spinal stabilization in another centre from our sub-region with good result. ${ }^{15}$ We also found it a safe and effective means of posterior spinal stabilization in ten of our patients.

Two of our patients with complete injury treated operatively did not improve; in fact, one of them died (see Table 6). Conservative management of complete SCI resulted in a better outcome as reported in a recent study from Pakistan. ${ }^{16}$ In their series of 54 patients with complete SCI, in which 50\% received surgical treatment, the operated group spent a longer period of time in rehabilitation $(P$-value $=0.002)$. They also had a longer hospital stay $(P$-value $=0.006)$, were associated with more complications, especially those related to infections $(P$-value $=0.002)$, and also had a significantly higher cost of treatment $(P$-value $<0.001)$ when compared with the group treated conservatively. ${ }^{16}$

However, the degree of improvement among patients with incomplete injury in the operative group (9 patients out of $15(60 \%)$, as shown in Table 6), justifies operative treatment, when indicated, in incomplete cord injury. This level of improvement may be related to the number of patients with intracanal foreign body $(n=7$, following gunshot injury), and such improvements have been documented in previous studies on gunshot spinal injury. ${ }^{17,18}$ Introduction of operative treatment when indicated in our management of spinal injury may be associated with a good outcome in a subset of patients with SCI, especially those with penetrating injuries. In this group, five of seven patients who received surgical treatment of the lesioned spine improved, whereas two remained in the same condition. None of the patients in this subgroup died.

Although the number of patients in this category is small for statistical conclusions, the results will justify a study of a larger population of this subgroup of SCI patients in the future. We recorded a mortality rate of $11.6 \%$ (10 patients), similar to what we had in our previous study, ${ }^{2}$ and the respiratory complications were the main cause of death (50\% of cases). This rate compares favourably with that of other studies ${ }^{4,6,9}$ in our subregion.

\section{CONCLUSION}

SCIs in southeast Nigeria are now mainly due to MVAs, because falls that used be the most common cause due to high frequency of falls from palm trees have dramatically decreased due to the replacement of tall species of palm trees over the years with short species that can be harvested without climbing. ${ }^{1}$ SCI also mainly affects male individuals in the most active periods of life and peak periods of incidence are represented by the main Christian festivities. Adequate education and sensitization of our people, especially our rulers, in implementing road maintenance culture and road safety measures may reduce MVAs, as happened with falls through replacement of tall species of palm trees by short ones.

Secondly, proper education of our population might bring about more carefulness during festive periods, especially while driving motor vehicles, and may also help change the negative attitude of our population towards the role of ambulance and emergency medical services in SCI care.

\section{DATA ARCHIVING}

There were no data to deposit.

\section{CONFLICT OF INTEREST}

The authors declare no conflict of interest.

\section{ACKNOWLEDGEMENTS}

We are grateful to Dr Emeka Okorie of the Division of Neurosurgery, Department of Surgery, Federal Medical Centre, Umuahia, Abia State, Nigeria, for helping in the collection of data. 
1 Okonkwo CA. Spinal cord injuries in Enugu, Nigeria-preventable accidents. Spinal Cord 1988; 26: 12-18.

2 Nwankwo OE, Katchy AU. Outcome of a 12-week programme for management of the spinal cord injured with participation of patient's relations at Hilltop Orthopaedic Hospital, Enugu, Nigeria. Spinal Cord 2003; 41: 129-133.

3 Nwankwo OE, Katchy AU. Management of the spinal cord injured using a 12-week programme in which patient's relations are involved: a report of 10-year experience. Niger J Orthop Trauma 2010; Vol 9: (No 1), 10-13.

4 Nwadinigwe CU, Iloabuchi TC, Nwabude IA. Traumatic spinal cord injuries (SCI): a study of 104 cases. Niger J Med 2004; 13: 161-165.

5 Swain A, Grundy D, Russel J. ABC of the Spinal Cord Injury: Articles Published in the BMJ. BMJ publication: London, 1991: 1-3.

6 Obalum DC, Giwa SO, Adekoya-Cole TO, Enweluzo GO. Profile of spinal injuries in Lagos, Nigeria. Spinal Cord 2009; 47: 134-137.

7 Draulans N, Kiekens C., Roels E, Peers K. Aetiology of spinal injuries in Sub-Saharan Africa. Spinal Cord 2011; 49: 1148-1154.

8 DeVivo MJ. Epidemiology of traumatic spinal cord injury: trends and future implications. Spinal Cord 2012; 50: 365-372.

9 Iwegbu CG. Traumatic paraplegia in Zaria, Nigeria: the case for a centre for injuries of the spine. Paraplegia, 1983; 21: 81-85.
10 Yeo JD, Walsh J, Rutkowski S, Soden R, Craven M, Middleton J.. Mortality following spinal cord injury. Spinal Cord 1998; 36: 329-336.

11 Burke DC. Spinal cord injury and seat belts. Med J Australia 1973; 2: 801-806.

12 Bedbrook G. Spinal injuries with tetraplegia and paraplegia. J Bone Joint Surg 1979; Vol 61 B: 267-284.

13 Rechtine GR 2nd. Nonoperative management and treatment of spinal cord injuries. Spine 2006; 31 (11 suppl): S 22-S 27.

14 Bono CM, Henry RF. Gunshot wounds of the spine. Spine J 2004; 4: 230-247.

15 Adeolu AA, Komolafe EO, Kolawole OA. The technique of using rigid vertical strut and spinal process wire for posterior spinal stabilisation. J Spinal Disord Tech 2011; 24 406-408.

16 Shamin MS, Ali SF, Enam SA. Non operative management is superior to surgical stabilisation in spine injury patients with complete neurological deficits: a perspective study from a developing world country, Pakistan. Surg Neurol Int 2011; 2: 166

17 Waters RL, Sie IH. Spinal cord injuries from gunshot wounds to the spine. Clin Orthop Relat Res 2003; 408: 120-125.

18 Yoshida GM, Garland D, Waters RL. Gunshot wounds to the spine. Orthop Clin North Am 1995; 26: 109-116. 